\title{
Migration issues in sintered-silver die attaches operating at high temperature
}

\author{
R. Riva ${ }^{\mathrm{a}}$, C. Buttay ${ }^{\mathrm{a}, *}$, B. Allard ${ }^{\mathrm{a}}$, P. Bevilacqua ${ }^{\mathrm{a}}$ \\ ${ }^{a}$ Université de Lyon, CNRS, INSA-Lyon, Laboratoire Ampère UMR 5005 F-69621, Villeurbanne, France
}

\begin{abstract}
Silver sintering is a promising alternative to high melting point (HMP) solders which contain lead. Indeed, it offers better thermal and electrical properties, and can operate at higher temperature. However, silver tends to migrate in presence of electric field, oxygen (or moisture) and high temperature, causing short circuits. In this paper, we assess the extend of this issue, and we evaluate the protective effect of a thin layer of parylene. It is shown that silver migration occurs rapidly (tens to hundred of hours at $300^{\circ} \mathrm{C}$ ), but that parylene offers a good mitigation of this issue.
\end{abstract}

Keywords: power electronics packaging, silver sintering, high temperature, migration, parylene

\section{Introduction}

\subsection{Silver sintering as a high temperature die-attach material}

With the recent introduction of Silicon-Carbide $(\mathrm{SiC})$ power devices, there is a growing interest in higher-temperature operating power systems. Indeed, $\mathrm{SiC}$ devices can operate at temperatures exceeding $300^{\circ} \mathrm{C}[1,2]$. However, to build a complete high temperature converter, many elements must be adapted to match the capability of the $\mathrm{SiC}$ power devices [3]. In particular, new bonding techniques are required to secure the $\mathrm{SiC}$ dies to the power circuit board (a ceramic substrate).

This die attach is classically made by soldering. Increasing the operating temperature of a system requires to use solder alloys with a higher melting point. Most common solder alloys (lead- or gold-based) have a melting point lower than $350^{\circ} \mathrm{C}$ [4]. To push the operating temperature capability further, some alternatives to soldering can be considered, such as Transient Liquid Phase Bonding (TLPB), or silver sintering. Both techniques have moderate process temperatures (lower than $300^{\circ} \mathrm{C}$ ), but result in a joint with a much higher melting point $\left(961^{\circ} \mathrm{C}\right.$ for silver).

\subsection{Migration of silver}

The process of silver sintering results in a solid silver joint, which is desirable, because silver has the highest thermal and electrical conductivity among metals. Also, it is non-toxic, and relatively inexpensive (especially compared to gold-based solder alloys). Sintered silver die attaches are currently used for mass production by Semikron [5]. Some reports indicate that the reliability of this technique is satisfying [6]. There is, however, one key issue that must be addressed for the high temperature operation of sintered-silver die attaches: at high temperature, when submitted to an electric field and in presence of

\footnotetext{
${ }^{*}$ Corresponding author

Email address: cyril . buttay@insa-lyon.fr (C. Buttay)
}

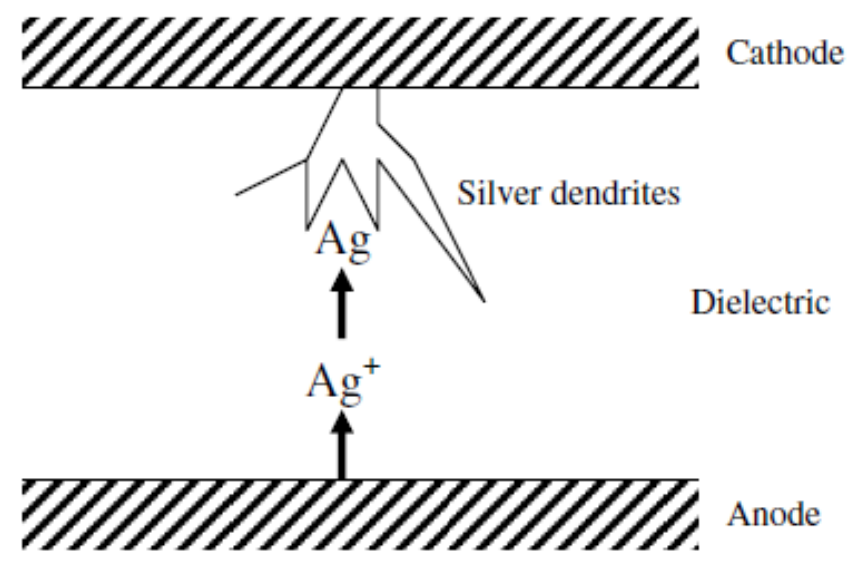

Figure 1: Conventional process of silver migration [12]

oxygen (or moisture), silver tends to migrate and form conductive filaments [7]. This phenomenon, which we will call "silver migration", is sometimes referred to as electromigration. It should not be confused with the "classical" electromigration phenomenon (displacement of atoms caused by an intense electric current). In a power electronic module, conductive silver filaments can cause short circuit failures.

Silver migration is the displacement of silver ions across a dielectric medium between two DC biased silver electrodes at temperatures ranging between $100{ }^{\circ} \mathrm{C}$ and $500{ }^{\circ} \mathrm{C}$ [7]. Such displacement eventually forms conductive filaments between the electrodes. In presence of oxygene (or moisture) and under an electric field, silver is oxidized at the positive electrode $[8,9,10]$ and dissolves forming silver ions $\mathrm{Ag}^{+}[8,11]$. Then, silver ions move under the influence of the electrical field $[7,10]$ from the positive electrode (anode) toward the negative electrode (cathode) (see figure 1) and form deposits in the form of needles or spikes [10]. Branching usually occurs at definite crystallographic angles, resulting in a characteristic "dendritic" structure. [10]. 


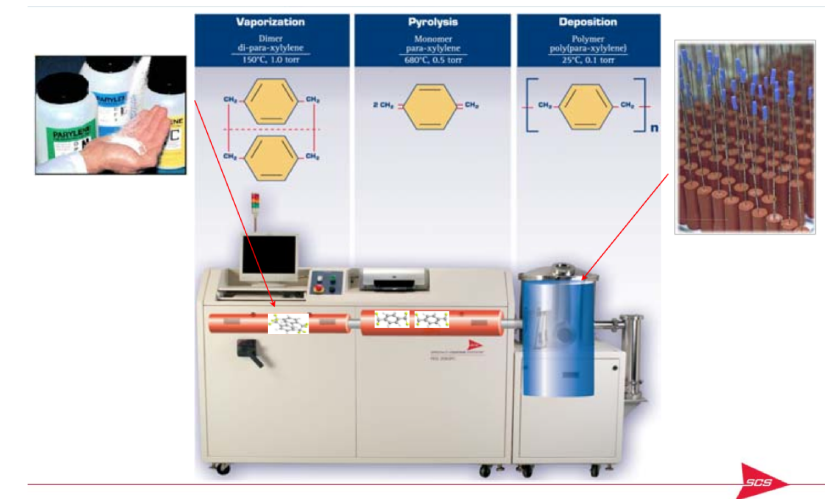

Figure 2: Principe of deposition process of parylene HT realized by the manufacturer SCS

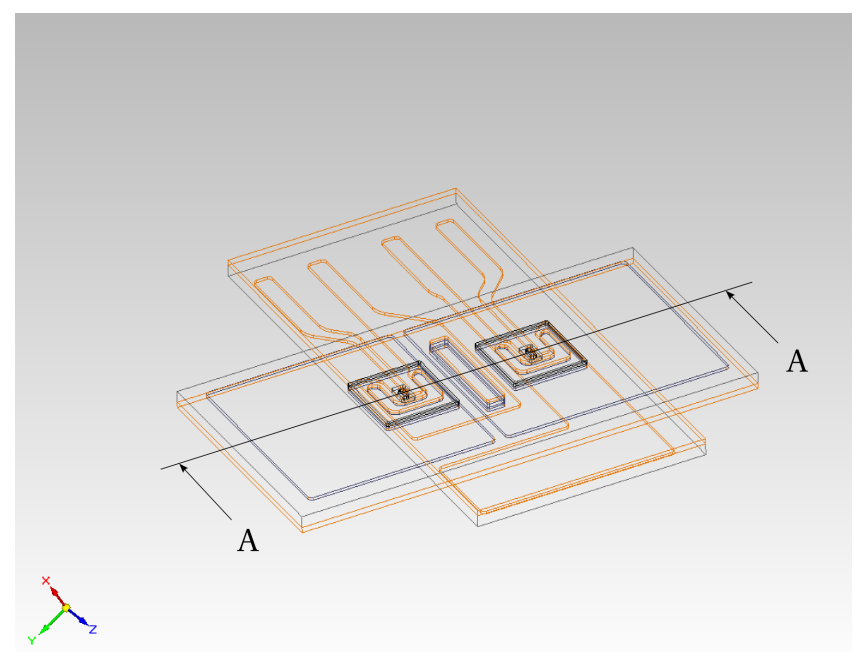

Figure 3: Drawing of the 3D structure of an inverteg leg built with two $\mathrm{SiC}$ JFET attached by silver sintering on two ceramik substrate.

Once a a filament has grown enough to connect both electrodes, a sudden drop in resistance occurs. So, a method to monitor silver migration is to measure the leakage current between two DC-biased electrodes. The lifetime of a test vehicle is defined as the operating time before the leakage current reaches an given value (e.g. $100 \mu \mathrm{A})$.

Three parameters influence the lifetime of a test vehicle [7].:

- electric field. An increase in the electric field decreases the lifetime ;

- temperature. An increase in the temperature decreases the lifetime;

- partial pressure of oxygen. An increase in the partial pressure of oxygen decreases the lifetime;

\subsection{High temperature passivation using parylene}

As seen above, silver migration is caused by oxygen or moisture. To provide a protection against oxygen and moisture, and to increase its voltage breakdown capability, a power module is usually filled with an encapsulant (often a silicone gel). For high temperature applications, parylene HT was found to be an attractive encapsulating material. Indeed, according to Diaham et al. [13], this material can operate at high temperature $(\leq 600$ $\left.{ }^{\circ} \mathrm{C}\right)$. It has been noticed that it can withstand 5000 minutes at $350^{\circ} \mathrm{C}$. Moreover, it has a high dielectric strength even at high temperature $\left(\approx 2 \mathrm{MV}\right.$ at $\left.350{ }^{\circ} \mathrm{C}\right)$. An other important criteria is its low permeability to oxygen, which means it can be a good oxygen barrier. Another fluorinated parylene (parylene F) that also offers high temperature capability is also available from various manufacturers. In this paper, we tested both the protective effect of parylene HT and parylene F.

The deposition process of parylene is interesting: because it is applied as a gas, it does not apply mechanical stress on the deposition surface and penetrates crevices and tight areas on multi-layer components, providing complete and uniform encapsulation. The deposition process is realized in a specialized vacuum deposition equipment in four step (see figure 2):

- The surface to be covered is placed on the deposition chamber, and a solid, granular raw material, called dimer is loaded on the equipment.

- The dimmer is heated under vacuum and vaporized into a dimeric gas

- The gas is then pyrolized to cleave the dimer to its monomeric form.

- The monomer gas deposits on all surfaces placed on the deposition chamber (at the room temperature) as a thin transparent polymer film.

To control the uniformity of the parylene deposit, a coating of parylene HT was realized by the manufacturer (SCS) on a 3D structure (see figure 3). This structure is an single phase inverter realized with two SiC JFET and two ceramic substrates. The die attach is made by silver sintering. To verify the coating thickness of the encapsulant, a cross section (see figure 4) was performed following the axis A-A shown in figure 3. Note that on the sample coated by parylene HT, no SiC JFET were used. It demonstrates that the parylene covered all surfaces of the structure, including the most intricate ones, especially between the two substrate. The parylene forms a thin transparent uniform layer. Moreover, the thickness of the layer is very regular, and corresponds to the specification given by the manufacturer $(\approx 20 \mu \mathrm{m})$.

\section{Experimental study}

\subsection{Test setup}

To assess the failure risk associated with silver migration, some simplified test vehicles were developped (figure 5): Two electrodes are stencil printed (using the same silver paste used for die attaches, Heraeus $11702 \mathrm{P} 2$ or NBETech Nanotach) on an alumina substrate. The silver electrodes are then sintered at $300^{\circ} \mathrm{C}$. 4 gap size are studied: $0.5,1,1.5$ and $2 \mathrm{~mm}$.

The test vehicules are then connected to the test system depicted in figure 6(a): a source and measure unit (Keithley 


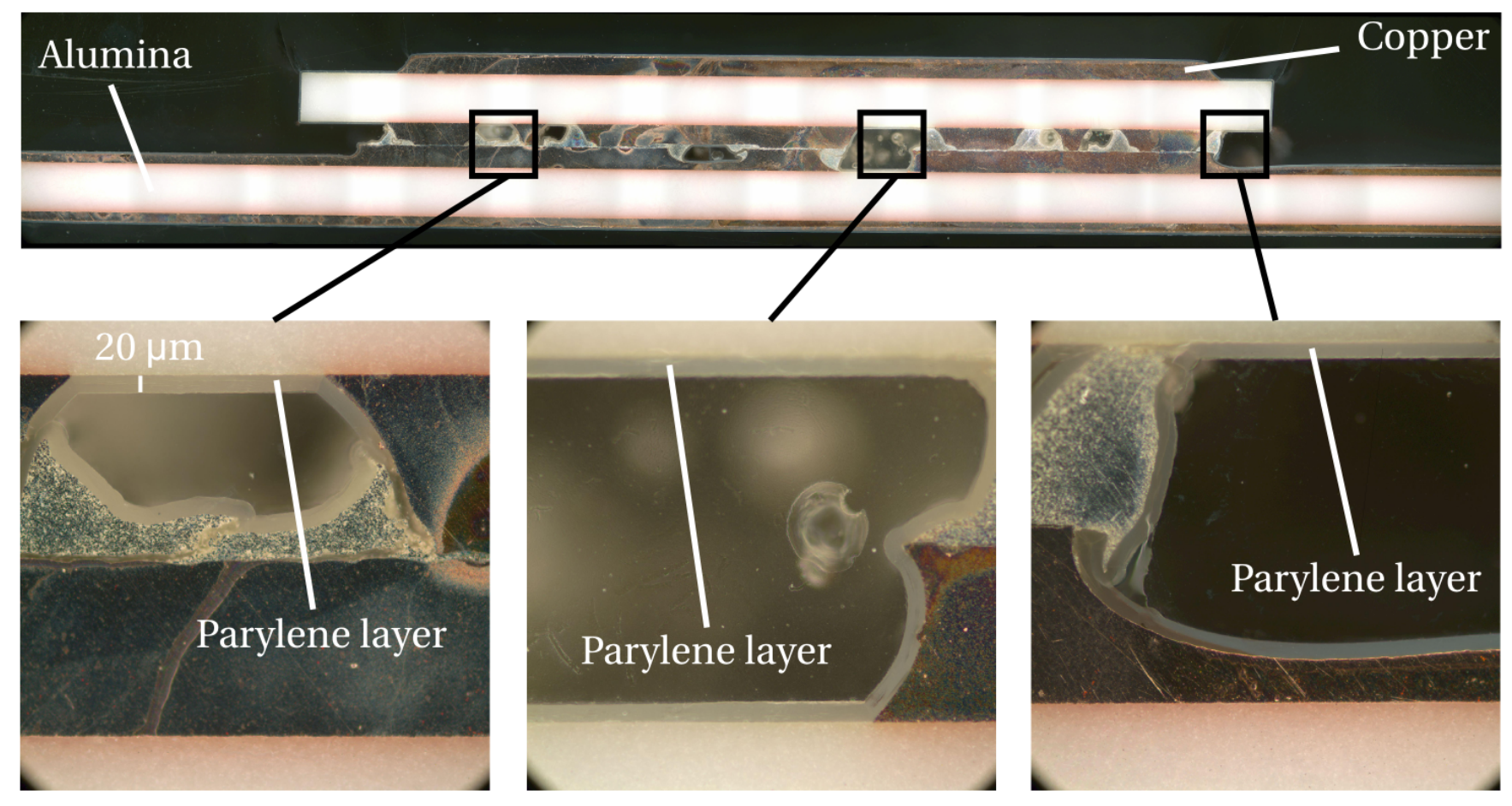

Figure 4: Cross section of the 3D structure in figure 3 (without SiC JFETs). Parylene HT forms a thin, transparent, uniform layer of thickness $20 \mu \mathrm{m}$, even in the most intricate cavities of the structure.

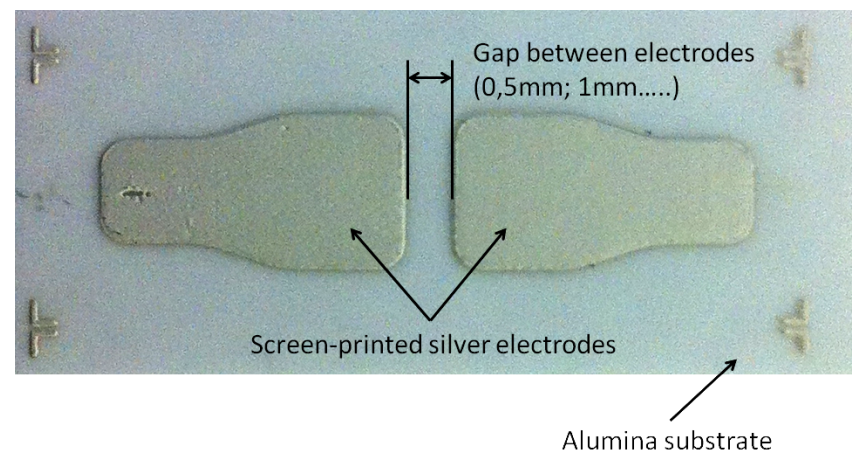

Figure 5: Structure of the test samples: silver electrodes are stencil-printed on an alumina substrate. The gap between the electrodes can be varied from 0.5 to $2 \mathrm{~mm}$. The size of the test vehicle is $35 \times 15 \mathrm{~mm}^{2}$.

SMU 2410) is used to bias the test vehicles with a high voltage $(1100 \mathrm{~V})$, and to periodically measure the resulting leakage current (with an accuracy of $6 \mathrm{nA}$ ). When the leakage current exceeds $100 \mu \mathrm{A}$, the test is stopped. This test is performed automatically on up to 10 test vehicles simultaneously, thanks to a computer and a high voltage switch system (Keithley 7001/7154). The test temperature is set by a forced convection oven (figure 6(b)). Figure 7 shows the evolution of the leakage current during a test, for five test samples. For the first $100 \mathrm{hrs}$, the leakage current remains at a low, relatively constant value. Then, as a the silver filament connects both electrodes, the leakage current increases dramatically, reaching $100 \mu \mathrm{A}$ and triggering the disconnection of the corresponding test sample. It can be seen that there is no detectable increase in the leakage current prior to the short-circuit. Furthermore, even if all samples were supposedly identical, and were placed in the same oven, their lifetime varies widely from one to another (130 to $210 \mathrm{hrs}$ in the case of fig. 7).

\subsection{Results}

\subsubsection{Effect of the gap size}

A first set of results is visible in figure 8. Each point corresponds to a test vehicle, and represents the delay before a short-circuit was detected between the electrodes. For each test vehicle, because of the inaccuracy of the screen printing process, the gap size was measured before the test. Two different silver pastes (the NBEtech material is based on silver nanoparticles while the Heraeus paste uses microparticles) were used to evaluate the possible effect of the paste composition on the migration phenomenon. No noticeable effect was found.

It can be seen that the lifetime increases with the gap size, which could be expected as an increase in gap size corresponds to a decrease in electric field (all samples are biased with a constant, $1100 \mathrm{~V}$ voltage, regardless of the gap size). It can be also noticed that even for $2 \mathrm{~mm}$ gaps, the delay remains fairly short $(350 \mathrm{~h})$ before failure. The results vary widely from one sample to the other, as can be seen from the large scattering in figure 8 . This can also be observed on the samples, as the silver filaments patterns are very different from one other (figure 9).

\subsubsection{Effect of the temperature}

Tests were performed at different temperatures $\left(250^{\circ} \mathrm{C}\right.$, $275^{\circ} \mathrm{C}$ and $\left.300^{\circ} \mathrm{C}\right)$, with the same gap $(1 \mathrm{~mm})$ and the same 


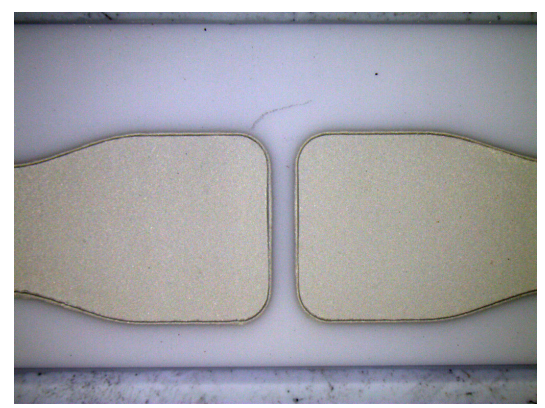

(a)

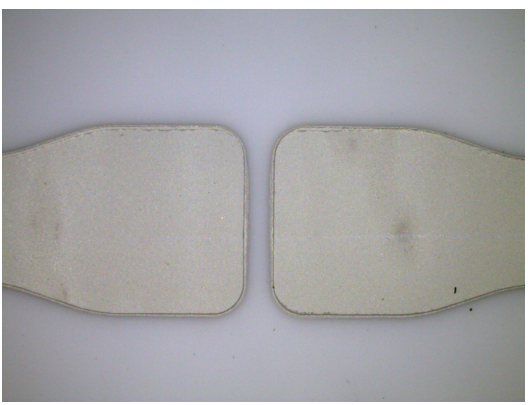

(d)

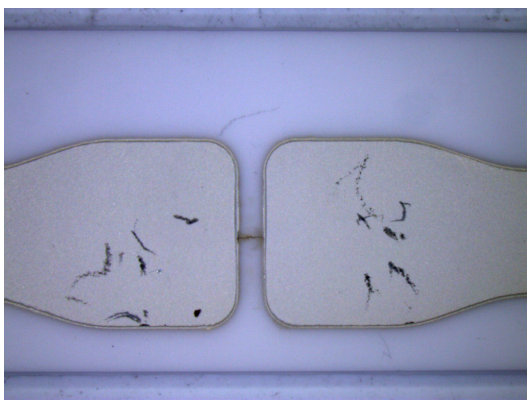

(b)

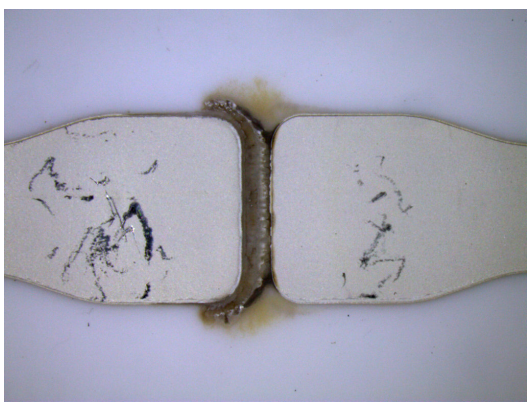

(e)

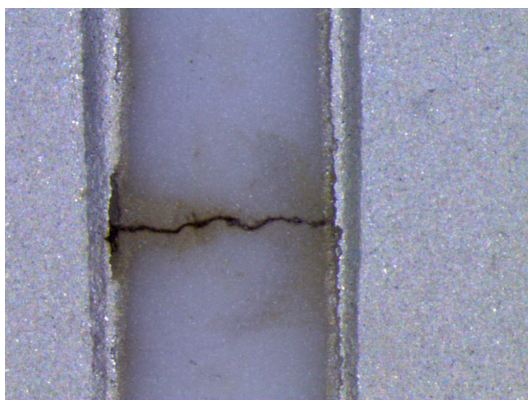

(c)

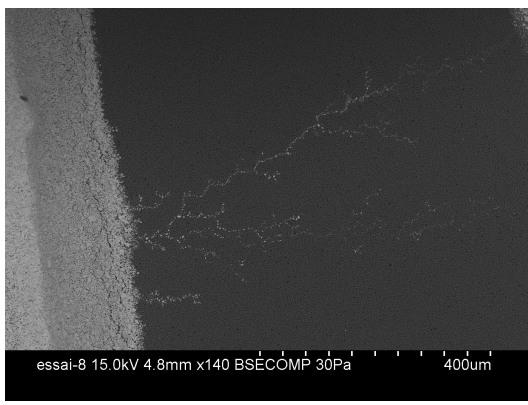

(f)

Figure 9: Pictures of some of the test samples, before the test (a) and (d), and after (b) and (e) respectively. An enlargement of (b) can be seen in (c), while an electron microscope view from another sample is visible in (f). It can be seen that the pattern and coverage of the silver deposit vary widely. All samples presented here have a $1 \mathrm{~mm}$ gap between electrodes

potential $(1100 \mathrm{~V})$. The results are presented in figure 10 with the $\mathrm{X}$-axis being the inverse of the absolute temperature (from $300^{\circ} \mathrm{C}-573 \mathrm{~K}-$ down to $250^{\circ} \mathrm{C}-523 \mathrm{~K}-$ ) and the $\mathrm{y}$-axis the inverse of the lifetime (50 up to $1000 \mathrm{hrs)} \mathrm{using} \mathrm{a} \mathrm{log} \mathrm{scale.}$

The Arrhenius equation can be used to describe the kinetics of temperature-dependant phenomenons:

$$
\frac{1}{t}=A \cdot \exp ^{\frac{Q}{K_{B} T}}
$$

where $\mathrm{t}$ is the delay before a short circuit, $\mathrm{Q}$ is the activation energy, $K_{B}$ is the Boltzmann constant, $\mathrm{A}$ a constant, and $\mathrm{T}$ the ambient temperature.

By fitting (1) to the data in figure 10 , the activation energy is found to be $1.71 \mathrm{eV}$ (and $A=2.15 \times 10^{13}$ ). Using these parameters, $(1)$ would predict a lifetime of $\approx 7700$ hours before short circuit for a temperature of $200^{\circ} \mathrm{C}$.

\subsubsection{Effect of a parylene layer}

To mitigate the issue of silver migration, some samples were coated with parylene [14], from two manufacturers (parylene F, from Comelec, and parylene HT from SCS). Both materials are deposited in vapor phase, resulting in a thin $(20 \mu \mathrm{m})$ and very uniform layer covering the entire test vehicle. The results can be seen in figure 11, for two ambient temperatures: 275 (fig. 11(a)) and $300^{\circ} \mathrm{C}$ (fig. 11(b)).

At $275^{\circ} \mathrm{C}$, only parylene $\mathrm{F}$ was tested and shows a dramatic improvement in the delay before failure: most of the tests were stopped after $1000 \mathrm{hrs}$ before any increase in leakage current could be measured. This confirms the good protection offered by parylene against oxygen. Note that the failure mode observed for the smaller gaps (lower than $0.2 \mathrm{~mm}$ ) is not related to silver migration but to electric arcing. Such small gaps were due to issues in the stencil printing process of the electrodes. In all other cases (gap $>0.5 \mathrm{~mm}$ ), the samples failed due to the silver migration (or the test were stopped before failure).

At $300^{\circ} \mathrm{C}$, parylene $\mathrm{F}$ brings no obvious improvement over un-protected samples. The parylene $\mathrm{F}$ layer shows signs of degradation, such as browning, after a few hundred hours in the oven. At the time of writing, the samples coated with parylene HT are under test and do not show any sign of degradation (no change in color, no blistering...), although they have been through several hundred hours of test. As for fig 11(a), the failure mode associated with the parylene HT samples presented in figure 11(b) is arcing due to the narrow gap and not to silver migration.

\subsection{Discussion}

At a $300^{\circ} \mathrm{C}$ ambient temperature, under a potential of $1100 \mathrm{~V}$, tests realised with different gaps demonstrate that the silver migration issue occurs rapidly. Increasing the gap between the electrodes decreases the electric field, and slows down the silver migration. Despite the relatively limited test condition evaluated, it appears that the growth of the silver filament can be described using an Arrhenius law. Above $200^{\circ} \mathrm{C}$, the lifetime of a $1 \mathrm{~mm}$-gap sample is found to be lower that $7700 \mathrm{hrs}$, which is relatively limited compared to the $50000 \mathrm{hrs}$ of operation expected for an aircraft.

The evolution of the leakage current with time shows no signature of the silver filament growth: the leakage current only 


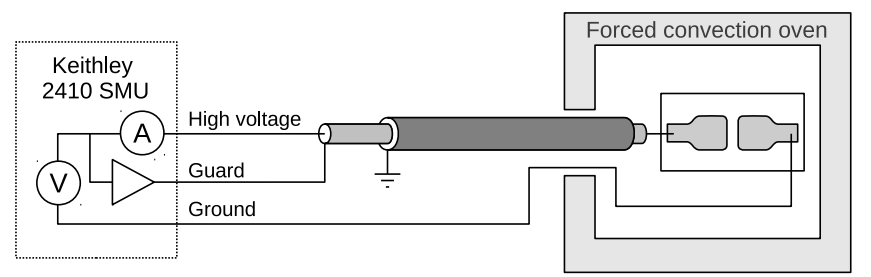

(a)

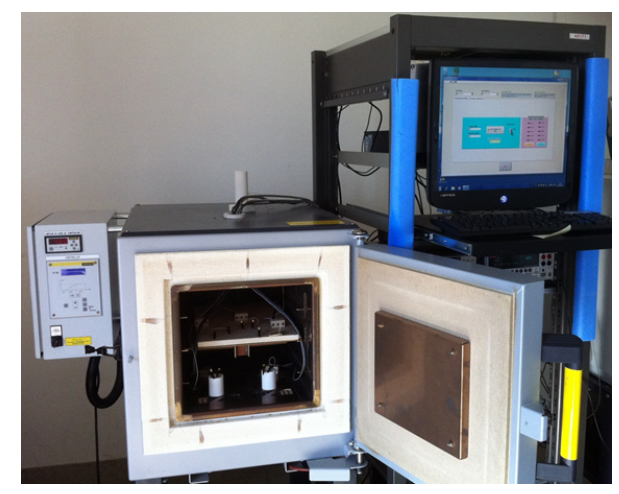

(b)

Figure 6: The test setup, allowing high voltage biasing $(1100 \mathrm{~V})$ of the test vehicles and measurement of the leakage current with a nanoamp accuracy (a). Up to 10 test vehicles can be tested simultaneously, thanks to a computer-controlled monitoring system associated with a high-voltage switch (b).

increases when the silver filament has bridged the gap between the electrodes. This means that it would be difficult to monitor the silver migration phenomenon through regular electrical controls.

The coating of the samples with a thin layer of parylene results in a dramatic improvement of the lifetime, as parylene prevents oxygen to reach the silver electrodes.

It should be noticed, however, that the test configuration used here was specifically developed to facilitate the occurrence of silver migration: in an actual power module, silver paste is only used as a die-attach material, while the conductive tracks are made of copper, possibly with a nickel-gold finish. The quantity of silver involved is much lower, and the electric field experienced by the silver layers possibly lower.

\section{Conclusion}

Silver migration has been identified as a possible failure mechanism for high temperature power modules. Parylene (F or HT), acting as a barrier to the oxygen, limit the phenomenon, and some samples have been demonstrated to operate for $1000 \mathrm{hrs}$ at $275^{\circ} \mathrm{C}$ without failure. Moreover, the test vehicles used in the present study constitute a "worst case" condition, as silver is normally used for the die attach only, not to form complete circuits. It can therefore be concluded that silver migration must be considered at the design stage, but can be prevented using proper design rules and passivation.

[1] J. Casady, R. Johnson, Status of silicon carbide (sic) as a widebandgap semiconductor for high-temperature applications: A review,

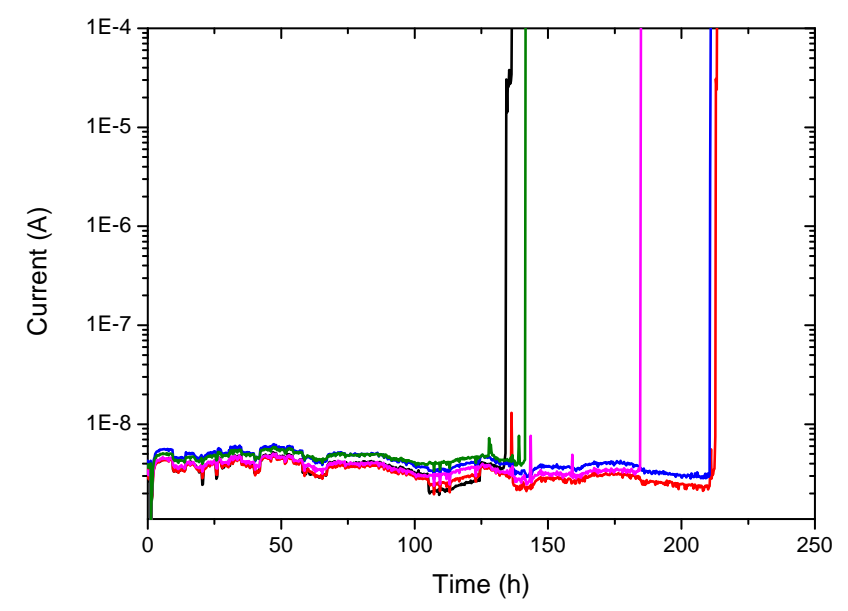

Figure 7: Plot of the leakage current versus the time for five test vehicles with the same gap. Test was realized at $300^{\circ} \mathrm{C}$ and a bias voltage of $1100 \mathrm{~V}$ between the electrodes.

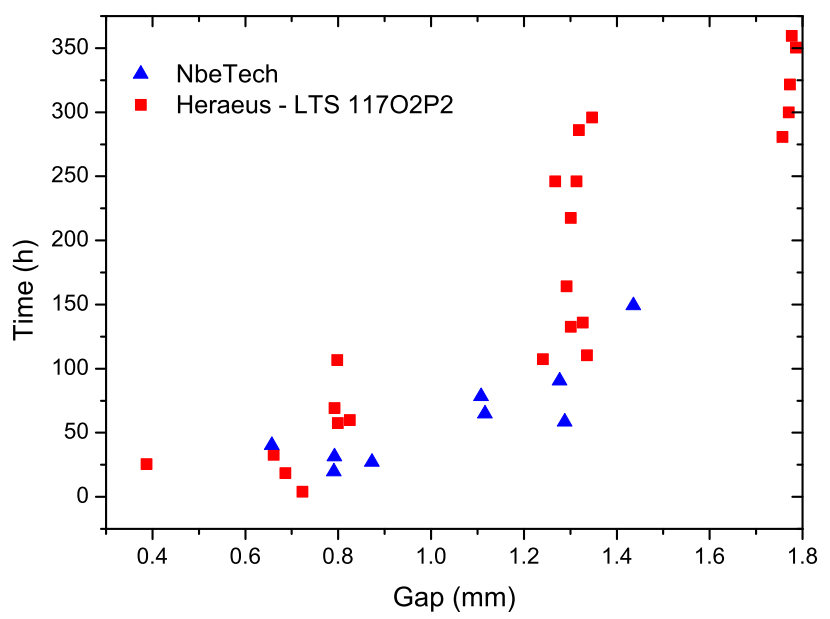

Figure 8: Time before a short circuit occurs betweens the electrodes of the test vehicle, as a function of the gap separating the electrodes, for a $300^{\circ} \mathrm{C}$ ambient temperature. Two silver pastes were studied.

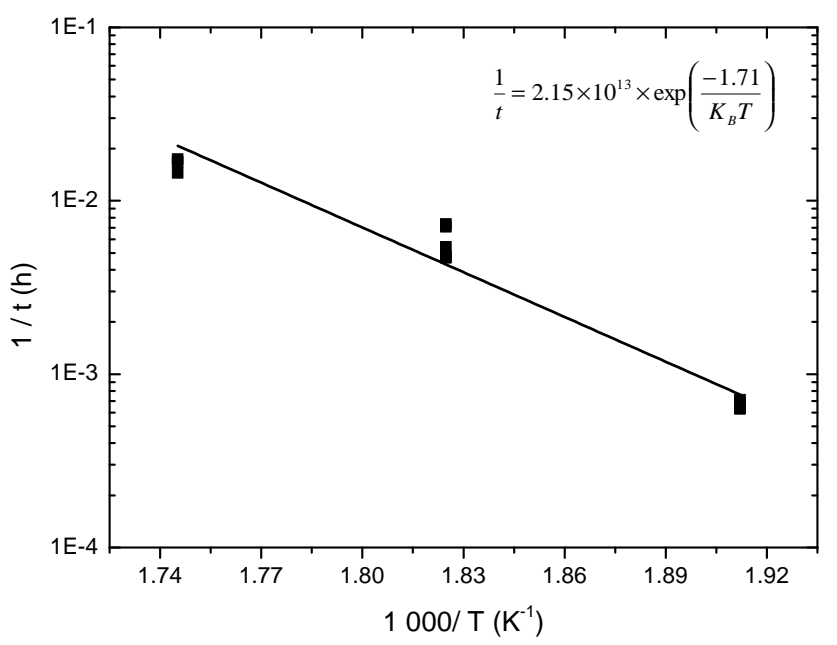

Figure 10: Arhenius plot of the lifetime of the samples (50 hrs to $1000 \mathrm{hrs}$ ) as a function of the temperature $\left(300^{\circ} \mathrm{C}\right.$ on the left, $250^{\circ} \mathrm{C}$ on the right). 


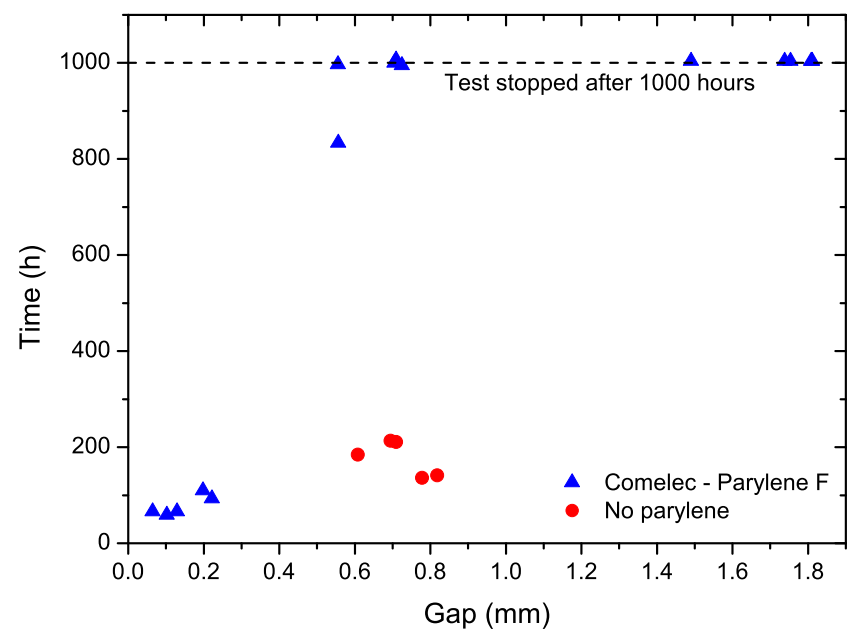

(a)

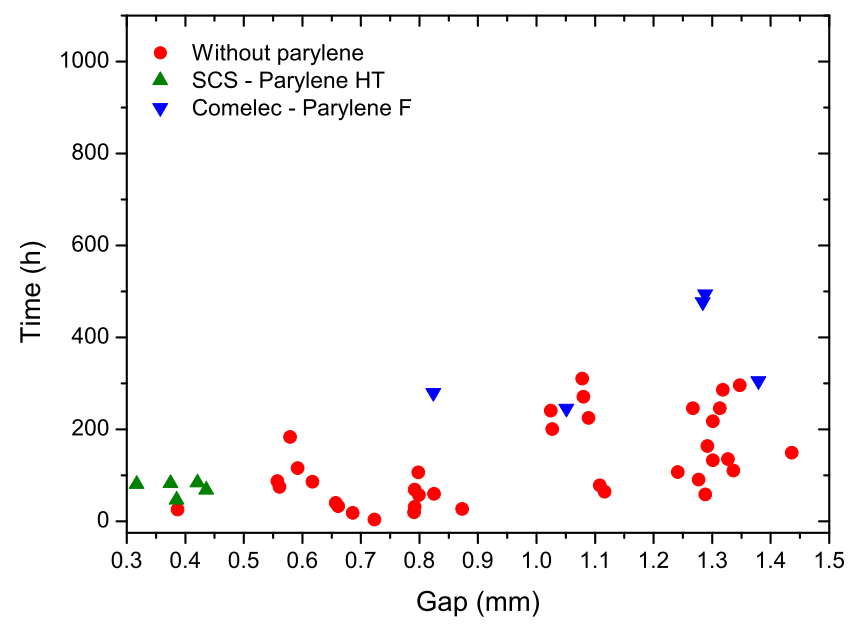

(b)

Figure 11: Time before a short circuit occurs between the electrodes of the test vehicle, as a function of the gap separating the electrodes, at a temperature of $275^{\circ} \mathrm{C}$ (a) and $300^{\circ} \mathrm{C}(\mathrm{b})$, for test vehicles with and without parylene protection

Solid-State Electronics 39 (10) (1996) 1409 - 1422. doi:10.1016/00381101(96)00045-7.

URL http://www.sciencedirect.com/science/article/pii/ 0038110196000457

[2] C. Raynaud, D. Tournier, H. Morel, D. Planson, Comparison of high voltage and high temperature performances of wide bandgap semiconductors for vertical power devices, Diamond and Related Materials 19 (1) (2010) 1 - 6. doi:DOI: 10.1016/j.diamond.2009.09.015.

URL http://www.sciencedirect.com/science/article/ B6TWV-4XCJ4M2-1/2/76c76271c9345bf77d4f c29077179d2a

[3] C. Buttay, D. Planson, B. Allard, D. Bergogne, P. Bevilacqua, C. Joubert, M. Lazar, C. Martin, H. Morel, D. Tournier, et al., State of the art of high temperature power electronics, Materials Science and Engineering: B 176 (4) (2011) 283-288.

[4] V. Manikam, K. Y. Cheong, Die attach materials for high temperature applications: A review, Components, Packaging and Manufacturing Technology, IEEE Transactions on 1 (4) (2011) $457-478$. doi:10.1109/TCPMT.2010.2100432.

[5] C. Goebl, P. Beckedahl, H. Braml, Low temperature sinter technology die attachment for automotive power electronic applications, in: Automotive Power Electronics, Paris, 2006, p. 5.

URL Www.semikron.com/internet/webcms/objects/pdf/ APE2006_Goebl.pdf
[6] M. Knoerr, S. Kraft, A. Schletz, Reliability assessment of sintered nanosilver die attachment for power semiconductors, in: Proceedings of the 12th Electronics Packaging Technology Conference (EPTC), IEEE, Singapore, 2010, pp. 56-61.

[7] Y. Mei, D. Ibitayo, X. Chen, S. Luo, G.-Q. Lu, Migration of sintered nanosilver die-attach material on alumina substrate at high temperatures, in: Proceedings of the IMAPS International Conference and Exhibition on on High Temperature Electronics (HiTEC 2010), IMAPS, albuquerque, NM, 2010, pp. 26-31.

[8] R. Manepalli, F. Stepniak, S. Bidstrup-Allen, P. A. Kohl, Silver metallization for advanced interconnects, Advanced Packaging, IEEE Transactions on 22 (1) (1999) 4-8. doi:10.1109/6040.746536.

[9] J. Steppan, J. Roth, L. Hall, D. Jeannotte, S. Carbone, A review of corrosion failure mechanisms during accelerated tests electrolytic metal migration, Journal of the electrochemical society 134 (1) (1987) 175-190.

[10] S. J. Krumbein, Metallic electromigration phenomena, Components, Hybrids, and Manufacturing Technology, IEEE Transactions on 11 (1) (1988) 5-15.

[11] G. Harsanyi, Electrochemical processes resulting in migrated short failures in microcircuits, Components, Packaging, and Manufacturing Technology, Part A, IEEE Transactions on 18 (3) (1995) 602-610. doi:10.1109/95.465159.

[12] S. Yang, J. Wu, A. Christou, Initial stage of silver electrochemical migration degradation, Microelectronics Reliability 46 (9) (2006) 1915-1921.

[13] S. Diaham, M.-L. Locatelli, Z. Valdez-Nava, Dielectrics for high temperature sic device insulation: Review of new polymeric and ceramic materials.

[14] R. Kumar, Parylene ht: A high temperature vapor phase polymer for electronics applications, in: Proceedings of the IMAPS International Conference and Exhibition on on High Temperature Electronics (HiTEC 2010), IMAPS, may, 2010, pp. 108-113. 